\title{
What affects how far individuals walk?
}

\author{
Aryan Hosseinzadeh ${ }^{1}$ (1)
}

Received: 17 July 2020 / Accepted: 2 February 2021 / Published online: 15 February 2021

(C) The Author(s) 2021 OPEN

\begin{abstract}
The number of studies that explore contributing factors that encourage individuals to do more walking trips is proliferated in recent years. However, there is still a lot to know about differentiating between short and long walking trips and their associated influencing factors. The current research investigated the impact of the influencing factors on the share of short and long walking trips across four different trips in 112 traffic analysis zones of Rasht, Iran. The share of walking trips was defined as the proportion of walking trips that originated/ended in an area on all trips that originated/ended in that area. In four trip purposes in short, long, and all trips, the factors associated with the share of walking in origins and destinations were investigated in 24 separate models. The factors included built environmental indices, such as transportation network connectivity and land-use variables, as well as socio-demographic. To differentiate between short and long walking trips, $600 \mathrm{~m}$ walking distance was recognized as a proxy. According to the results, the population density was found significantly increase share of walking in both the origins and destinations of short walking trips. Moreover, the models' goodness of fits were relatively higher in short walking trips comparing long walking trips. This research's findings would give a profound assessment to city planners and decision makers who favor expanding walking as a sustainable mode of transportation.
\end{abstract}

Keywords Walking · Built environment · Transportation network design · Connectivity · Population density · Land use diversity

\section{Introduction}

As a basic transportation mode, walking plays a significant role in urban transportation [1, 2]. Walking can provide access to other motorized modes and also considered a stand-alone independent travel mode, especially shorter trips. Promoting walking is important due to its enormous benefits, including the environment, economy and public health [3]. Transportation network Design, land-use Diversity and population Density, Destination accessibility and Distance to transit (5D's) were introduced as built environmental determinants of walking in the literature $[1,4,5]$.

Although a wide range of studies investigated the relationship between $\mathrm{BE}$ and walking, just a few investigated how this relationship would be changed if short and long walking trips are considered separately. In other words, it would help to identify which criteria are more influential on short trips versus long ones. Furthermore, most of the studies only explore the residential place, and the impact of trip destination zones is unclear. Finally, most of the objective studies were conducted in a small area of a city in a developed country, while the study area in the current analysis is a city in a developing country.

The current study addresses influencing factors on the share of walking in trip origin/destination zones in short, long and all walking trips, with different trip purposes. To do so, the effective factors on the share of walking trips in 112 Rasht traffic analysis zones (TAZs) were modeled. The share of walking trips was defined as the proportion of walking trips that originated/ended in a TAZ on all modes.

Aryan Hosseinzadeh, aryan.hosseinzadeh@louisville.edu | 'Department of Civil and Environmental Engineering, University of Louisville, W.S. Speed, Louisville, KY 40292, USA. 
Considering the possibility of different influences of BE factors on origins and destinations of the share of walking trips, origins and destinations were modeled separately.

The author's previous studies using the same dataset developed walkability indices across trip purposes [6] and investigated the association between built environmental factors on the share of walking trips across different trip purposes [7]. The exploration on the association of built environmental factors and walking is continued in this study by decomposing the trips to short and long walking trips and examine how the impact would be different.

This study would guide policymakers to identify which $\mathrm{BE}$ factors can encourage people to walk more in both short and long trips. The main question is whether a significant difference between the influencing factors in short and long trips is there. The zone-based studies in the scope of a city provide a proper foundation for decision-makers in long-term planning and policymaking. In this study, a zonal-based approach has been considered to evaluate walking conditions in Rasht, Iran.

The remainder of this paper is structured herein: first, an overview of indices associated with each $\mathrm{BE}$ criterion in the literature and studies that have accounted for the length of walking trips. The third section is the method, an overview of the case study and a summary of the descriptive statistics. The results and conclusion are the next sections of the paper.

\section{Literature review}

\subsection{Built environment criteria}

\subsubsection{Design}

Design is a proxy of street network characteristics within an area. Quite a few indices were recommended to encapsulate transportation network design effects on walking [8-10]. Design factors such as intersection density [11], cul-de-sac density [12], percentage of 4-way intersection [9], street density [9], Connected Node Ratio $[9,13]$, gamma and alpha indices [10] were employed in various studies in the literature as the proxy of design criteria. Data availability and researchers' preferences were the main determinants of which index to use in previous studies [11, 14-17]. Multicollinearity among indices was the major deterrent to use the factors at once in previous studies. However, some studies combined several indices to extract a single index by applying Principal Component Analysis (PCA) [8]. Implementing PCA method, Hatamzadeh et al. suggested two combined indices that have resulted from PCA [18]. According to their results, two elements were derived, which captured about $70 \%$ of the variations of all design indices [18]. The first element was the compound of percentages of four-way intersections and connected node ratio (node connectivity). The second element included the ratio of minor streets to major streets and street density (link connectivity) (for more details, see [18]).

\subsubsection{Diversity}

The mixture of different land-uses in a neighborhood represents diversity [1]. Diversity has been introduced as the most influential BE criteria in the last two decades of studies [19]. Bentley et al. (2018) found a positive association between walking and diversity by accounting for the changes over the years and variations in individuals' walking [20].

To capture the diversity of land-use, various indices are proposed. Table 1 shows the two more common diversity indices in the literature. Although the entropy index was extensively utilized in previous studies [1, 9, 21], Christian et al. (2011) explored the variation of entropy in different scenarios. They suggested that the entropy index could greatly change due to a slight alteration in land-use categorization [22]. Sugiyama et al. (2019) implemented isometric substitution analysis and called the entropy index's performance under question [23]. On the other hand, Ewing et al. (2015) considered another diversity index, high job-population balance in a zone, and resulted in a $15 \%$ decrease in vehicle mile traveled in that zone [24]. Cervero and Duncan (2006) suggested that job-population index is superior in comparing other indices such as entropy [25].

Table 1 Diversity indices proposed in the literature

\begin{tabular}{|c|c|}
\hline Diversity indices & Description \\
\hline Entropy & $\begin{array}{l}-\frac{\sum_{\mathrm{i}=1}^{\mathrm{n}} \mathrm{p}_{\mathrm{i}} \log \mathrm{p}_{\mathrm{i}}}{\operatorname{logn}} \\
\mathrm{P}_{\mathrm{i}}: \text { Percentage } \\
\text { of land-use } \mathrm{i} \\
\text { (area-based) } \\
\mathrm{n}: \text { Total number } \\
\text { of land-uses }\end{array}$ \\
\hline Job-population balance & $\begin{array}{c}1-\mid \frac{\text { Job- } 0.2 \times \text { Pop }}{\text { Job+0.2×Pop }} \\
\text { job: Number of } \\
\text { jobs within a } \\
\text { specific TAZ } \\
\text { pop: Number } \\
\text { of residents } \\
\text { within a } \\
\text { specific TAZ }\end{array}$ \\
\hline
\end{tabular}




\subsubsection{Density}

As a BE criterion, population density has defined the proportion of a specific zone's population to the area of that zone $[9,26]$. A higher ratio can be found in the Central Business District (CBD) of cities, in which walking is more encouraged [27].

\subsubsection{Distance to Transit}

Distance to transit was introduced as another built environmental factor affecting walking $[28,29]$. Ewing and Cervero (2010) employed the shortest distance of an individual's home/workplace to an adjacent public transit stop as an indicator of this criterion [1]. The total road network coverage of the public transit per TAZ, the average distance between stations in a TAZ and public transit stations density in a TAZ were also used to represent distance to transit criteria [24].

\subsubsection{Destination Accessibility}

Destination accessibility is defined as the ease of accessing different destination locations. The distance can measure it to various destinations or the number of destinations around a location [1].

\subsection{Short and long walking trips}

A limited number of studies were divided into short and long trips based on their lengths. Ferrer et al. (2015) considered a duration of less than $30-45$ min of walking as a short walking trip [30]. Mackett (2003) has investigated the potential of mode transfer on short trips. In this study, the factors that can induce mode change on short trips were identified [31].

How long do people usually walk? It is an important question in walking literature. lacono et al. (2008) assessed distance-decay functions for different modes and various trip purposes. They showed how the tendency of walking decreases as the distance increases and also how the travel behavior changes based on the purpose of the trip [32].

Short walking trips are generally mentioned in previous studies when their distance to public transit was focused. Ewing and Cervero (2010) reported a meta-analysis showing a public transport demand elasticity of -0.29 , suggesting a $10 \%$ increase in distance to a public transit stop would decrease public transport-use by approximately $3 \%$ of trips [1]. A study of the elderly in Florida concluded that the people who have lived within $200 \mathrm{~m}$ of the bus route were three times more likely to use the bus than those living $400 \mathrm{~m}$ from the bus stop [33]. As a rule of thumb, $400 \mathrm{~m}$ (a quarter-mile) or multiples, such as $800 \mathrm{~m}$ (half a mile), are considered to be the key distances in network and service planning [34].

\subsection{Walking and trip purposes}

The impact of trip purposes on walking has been explored in some of the studies. Yang and Diez-Roux indicated that walking distance and duration are significantly associated with seven trip purposes [35]. lacono et al. (2008) found people had less desire to walk on shopping trips rather than entertainment trips [32]. In another study, work and shopping were explored as two different purposes that reveal the influencing factors are different in two categories [36]. Gehrke and Clifton found a similar outcome for walking for transportation and discretionary trips [37]. Handy (1992) found that more walkable areas encourage individuals to run their errands on foot [38]. She also found that for purposes such as exercise, the BE impact is not discernable [38]. In a study among older adults, trip purposes are introduced as the main determinant of walking distance [39]. Habibian and Hosseinzadeh (2018) developed a walkability index across different trip purposes, which suggests the role of built environment criteria could be different based on trip purposes [18]. In summary, although there is a great deal of studies that have focused on trip purposes, none of them attempted to test how the role of BE factors on walking could be different based on walking distance.

\section{Study area}

The city of Rasht is the largest city in northern Iran along the Caspian Sea coast with a population of about 640,000 as of 2007. Figure 1 shows the urban form of Rasht and its 112 TAZs. Rudimentary street networks, unorganized and dense residential areas, and weak infrastructure compose a significant part of the city's spatial structure [13]. A significant burden is placed on the city center because the streets originating there and the ring roads that connect them shape the street layout's primary structure [40]. As the prominent retail center, the traditional bazaar (TAZ 1) is located in the city's heart, which causes congestion in the central part of the city. The share of public transit in the city is about $2 \%$, which could be because $86.6 \%$ of the streets are minor ones and that the public transit is not properly developed. In addition, the low rate of car ownership (mean: 0.57 vehicles per household) and weak organization of taxis, walking has become a favorable mode of transportation [41, 42]. Taxis in Rasht are shared-cars that should pass in an assigned direction, not common taxis worldwide. Furthermore, urban planning studies showed that the city of Rasht is treated as a compact city; thus, 


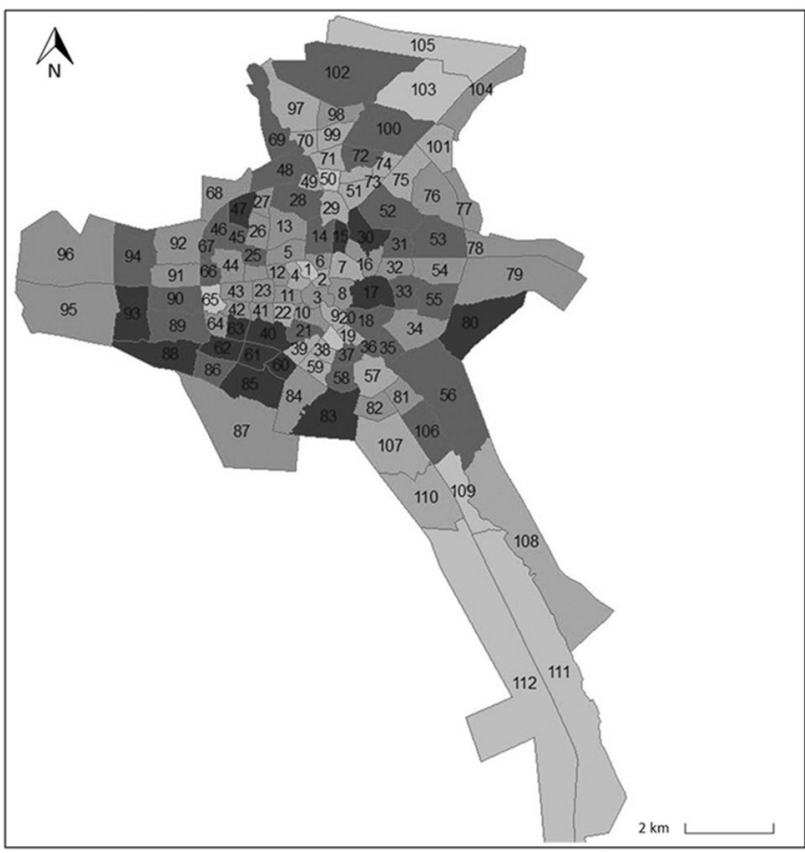

Fig. 1 Traffic analysis zones in Rasht

major part of trips are in walkable distances [42]. The share of walking in this city is $31.2 \%$ of all trips.

\section{Methodology}

\subsection{Data description}

Data from the Rasht Household Travel Survey (RHTS) of 2007 was used in this study. A questionnaire was distributed among more than 5,000 households in $112 \mathrm{TAZs}$. The survey aimed to gather a detailed trip description of all members of the participating household. Travel modes, the starting and ending time of the trip, and the trip purpose were asked to fill out by each family member on a specific day. In addition, information about the vehicles' ownership by type (e.g., car, motorcycle, and bicycle) and household size, participants socio-demographic, such as age, gender and job status, were also gathered [40]. It is worth noting that as RHTS has not been updated since 2007 , no more recent data has been available.

The data consists of more than 5,000 households, 17,000 individuals and 30,000 trips $(5,501$ work trips, 4,896 educational trips, 2,737 shopping trips and 15,355 return-to-home trips). According to RHTS, more than 95\% of work trips, educational trips and shopping trips were home-based. The walk-share related to shopping was higher than others; although the walk-share in all trips was $31 \%, 47 \%$ of shopping trips used walking as the primary transportation mode. The average equivalent radius of TAZs is about $400 \mathrm{~m}$.

\subsubsection{Socio-demographic}

Socio-economic factors in TAZs, including average age, household size, bike ownership, motorcycle ownership and car ownership, were calculated. Descriptive statistics are provided in the first part of Table 2.

\subsubsection{Design}

Design indices are derived employing the geographic information system (GIS) database of the transportation network of Rasht (gathered by RHTS). ARC GIS software has been employed to derive indices. The second part of Table 2 shows descriptive statistics of the design indices.

\subsubsection{Diversity}

Land-use diversity variables are derived using the RHTS land-use database. The third part of Table 2 shows the descriptive statistics of the obtained diversity variables.

\subsubsection{Density}

The calculated population density of each zone is shown in the fourth part of Table 2 .

\subsection{Modeling approach}

In this study, linear regression analysis was used to model the attributing factors on the share of short and long walking trips. This approach has been previously utilized in similar disciplines such as estimating subway station demands [43] and transit ridership [44] to account for BE factors. The share of walking trips was defined as the proportion of walking trips that originated/ended in a TAZ on all modes. The share of short and long walking trips in a zone for each trip purpose was considered a dependent variable. Socio-demographic characteristics and built environment criteria were used as independent variables. Considering origins/destination in short/long/all trips and four trip purposes resulted in 24 models $\left(2^{*} 3^{*} 4=24\right)$. The model can be represented in Eq. 1:

$\mathrm{Y}_{\mathrm{i}}=\beta_{1}+\beta_{2} \mathrm{x}_{2 \mathrm{i}}+\beta_{3} \mathrm{x}_{3 \mathrm{i}}+\cdots+\mathrm{u}_{\mathrm{i}}$

A linear regression model assumes that the association between the share of walking $Y_{i}$ and each of the explanatory variables is linear (Eq. 1). This relationship is modeled through an error term $u_{i}$, an unobserved random variable that adds noise to Eq. 1. In developing Eq. 1, the validity of 
Table 2 Zone-based descriptive statistics

\begin{tabular}{|c|c|c|c|c|c|c|}
\hline & & Average & $\begin{array}{l}\text { Standard } \\
\text { deviation }\end{array}$ & Min & Max & Units \\
\hline \multicolumn{7}{|c|}{ Part 1-Socio-economic variables } \\
\hline $1-1$ & Age average & 30.01 & 2.83 & 22.33 & 40.25 & year \\
\hline $1-2$ & Household size & 3.51 & 0.19 & 3 & 4.33 & person \\
\hline $1-3$ & Average bike ownership & 0.66 & 0.12 & 0.375 & 1.008 & - \\
\hline $1-4$ & Average motor ownership & 0.12 & 0.07 & 0 & 0.43 & - \\
\hline $1-5$ & Average car ownership & 0.57 & 0.24 & 0.26 & 0.95 & - \\
\hline \multicolumn{7}{|c|}{ Part 2-Connectivity indices } \\
\hline $2-1$ & Intersection density & 244.5 & 134.32 & 1.24 & 656.29 & $1 / \mathrm{km}^{2}$ \\
\hline $2-2$ & Percentage of 4-way intersections & 14.1 & 6.44 & 0 & 38.9 & - \\
\hline $2-3$ & Cul-de-sac density & 146.11 & 91.01 & 0 & 407.8 & $1 / \mathrm{km}^{2}$ \\
\hline $2-4$ & Number of cul-de-sac & 75 & 62.6 & 0 & 363 & - \\
\hline $2-5$ & Number of 3-way & 104 & 80.6 & 3 & 449 & - \\
\hline $2-6$ & Number of 4-way & 15 & 11.96 & 0 & 69 & - \\
\hline $2-7$ & Ratio of minor streets to major streets & 11.57 & 25.63 & 0 & 187.56 & - \\
\hline $2-8$ & Street density & 0.017 & 0.0084 & 0.004 & 0.035 & $\mathrm{~m} / \mathrm{km}^{2}$ \\
\hline $2-9$ & 3-way intersection density & 210.88 & 116.92 & 1.24 & 535 & $1 / \mathrm{km}^{2}$ \\
\hline $2-10$ & 4-way intersection density & 33.62 & 23.98 & 0 & 121.2 & $1 / \mathrm{km}^{2}$ \\
\hline $2-11$ & Connected node ratio & 0.62 & 0.1 & 0.4 & 1 & - \\
\hline $2-12$ & Ratio of links to nodes & 1.86 & 0.2 & 1.55 & 2.25 & $1 / \mathrm{m}$ \\
\hline $2-13$ & Gamma index & 0.39 & 0.05 & 0.33 & 0.63 & - \\
\hline $2-14$ & Alpha index & 0.09 & 0.059 & 0.01 & 0.36 & - \\
\hline $2-15$ & Percentage of 3-way intersections & 85.9 & 10.32 & 61.09 & 100 & \\
\hline $2-16$ & Number of major 3-way intersections & 7.61 & 7.48 & 0 & 49 & - \\
\hline $2-17$ & Number of major 4-way intersections & 1.34 & 1.67 & 0 & 11 & - \\
\hline $2-18$ & Ratio of cul-de-sac to nodes & 37.01 & 9.22 & 0 & 60 & - \\
\hline $2-19$ & Major street density & 3653.4 & 2967.5 & 0 & $16,149.4$ & $\mathrm{~m} / \mathrm{km}^{2}$ \\
\hline $2-20$ & Minor street density & 21,648 & 8836.3 & 610 & 36,898 & $\mathrm{~m} / \mathrm{km}^{2}$ \\
\hline $2-21$ & Average link length & 54.37 & 24.95 & 27.2 & 227.46 & $\mathrm{~m}$ \\
\hline $2-22$ & Node connectivity & 0.60 & 0.13 & 0.32 & 1.34 & - \\
\hline $2-23$ & Link connectivity & 18.30 & 26.20 & 0.03 & 166.50 & - \\
\hline \multicolumn{7}{|c|}{ Part3-Diversity indices } \\
\hline $3-1$ & Entropy index & 0.33 & 0.19 & 0 & 0.83 & - \\
\hline $3-2$ & Herfindal-Hershman index & 0.72 & 0.18 & 0.29 & 1 & - \\
\hline $3-3$ & Mixed-use index & 35.8 & 11.3 & 1.64 & 50 & - \\
\hline $3-4$ & Job-pop balance & 0.56 & 0.29 & 0 & 1 & \\
\hline \multicolumn{7}{|c|}{ Part4-Density index } \\
\hline $4-1$ & Population density & 10,100 & 6600 & 0 & 28,700 & $1 / \mathrm{km}^{2}$ \\
\hline \multicolumn{7}{|c|}{ Part5-Destination accessibility indices } \\
\hline $5-1$ & Areal distance to CBD & 2629 & 1712 & 0 & 10,626 & $\mathrm{~m}$ \\
\hline $5-2$ & Network distance to CBD & 3334 & 2318 & 0 & 14,782 & $\mathrm{~m}$ \\
\hline
\end{tabular}

assumptions such as multicollinearity among independent variables and homoscedasticity of the erorr term were tested to ensure no assumptions violations exist.

\subsection{Analyzing process}

An aggregated analysis was utilized as each TAZ acted as a unit of analysis. Four trip purposes were considered in walking trips modeling (i.e., work, education, shopping and return to home). Descriptive statistics, number and percentage of each trip purpose were presented in Tables 3 and 4. 
Fig. 2 Short and long trips threshold

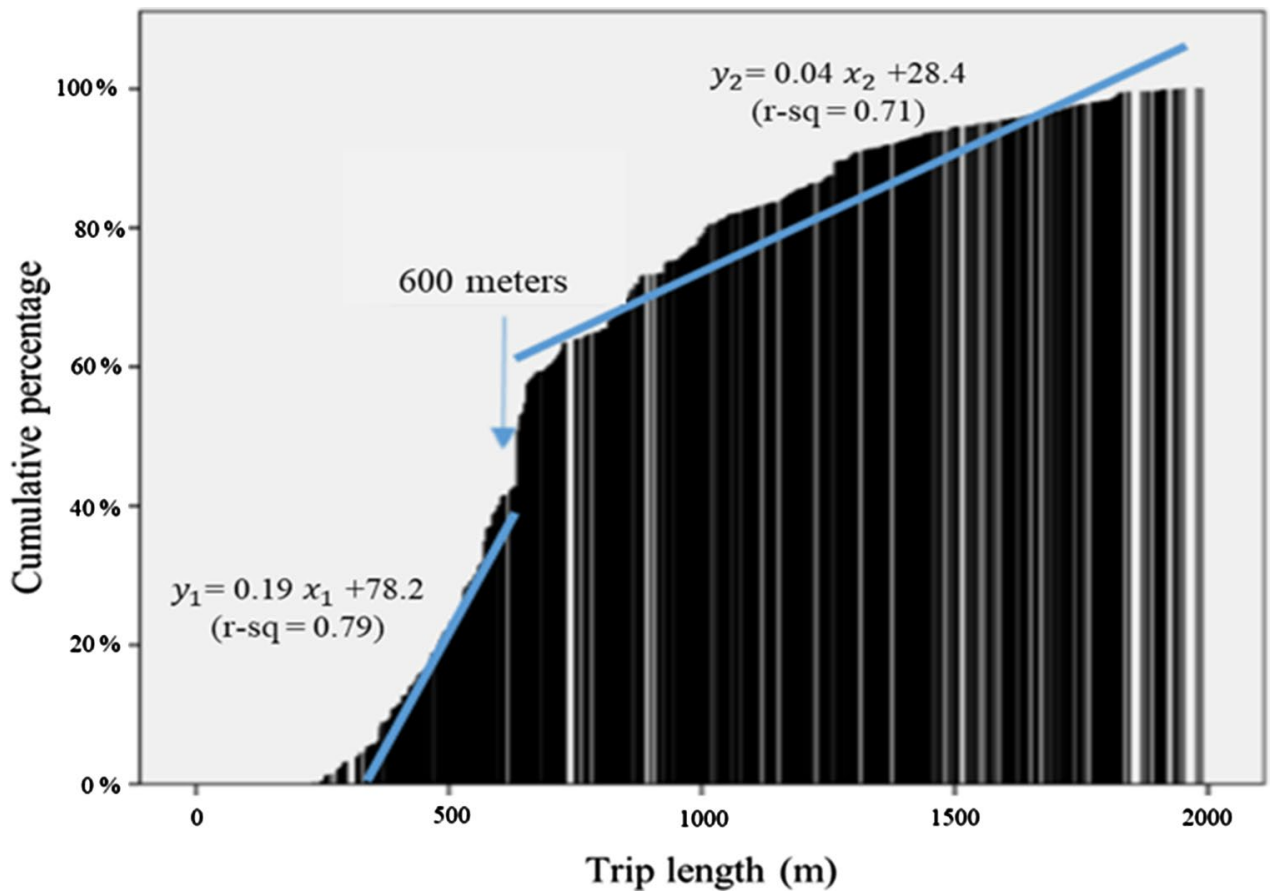

\subsection{Short and long walking trip threshold}

In this section, an attempt was conducted to identify a boundary for short and long trips. The visualization of cumulative percentage of walking trips versus trip length (Fig. 2) showed there is a discernible difference in slopes before $\left(m_{1}=0.19\right)$ and after $\left(m_{2}=0.04\right)$ the threshold (i.e., 600-m trips). Moreover, most of the literature studies introduced $400 \mathrm{~m}$ and $800 \mathrm{~m}$ as the two desirable distances for walking. The threshold was also the average of these

Table 3 Number and percentage (pct) of the walking trip on each trip purpose

\begin{tabular}{llll}
\hline & Walking trips & All modes trips & $\begin{array}{l}\text { Pct. of } \\
\text { walking } \\
\text { trips }\end{array}$ \\
\hline Work & 892 & 5501 & 16.2 \\
Educational & 1805 & 4896 & 36.9 \\
Shopping & 1295 & 2737 & 47.3 \\
Return to home & 4901 & 15,355 & 31.9 \\
\hline
\end{tabular}

two distances. For these reasons, $600 \mathrm{~m}$ was chosen as the threshold for short and long trips. As mentioned before, since there was no actual length of each trip in the database, the distance between centroids of origin and destination TAZs was considered the trips' length. As long as Rasht TAZs had the same approximate area of the zones (TAZs in CBD, not the suburb), the error is not substansial. In inter-zonal trips, the distance between centers of equivalent zone radius was considered as the walking trips' distances. In intra-zone walking trips, the equivalent radius of each TAZ was considered as the walk length. The data of the precise travel distance and time in walking is always a concern in household travel surveys. Agrawal and Schimek (2007), using National Household Travel Survey data from the United States in 2001, acknowledge that because many individuals have an imprecise sense of distances, the trip distance is unlikely to be estimated accurately [45, 46]. In this study, the main mode of the trip is the only one reported. For instance, if an individual walked to public transit and used it to reach the destination, public transit was reported as their trip mode.
Table 4 Number and percentage of the short and long walking trip on each trip purpose

\begin{tabular}{|c|c|c|c|c|c|c|c|c|}
\hline & \multicolumn{2}{|l|}{ Work } & \multicolumn{2}{|c|}{ Educational } & \multicolumn{2}{|c|}{ Shopping } & \multicolumn{2}{|c|}{ Return to home } \\
\hline & Number & Percent & Number & Percent & Number & Percent & Number & Percent \\
\hline Short walking trips & 359 & 40.3 & 603 & 33.5 & 589 & 45.5 & 1835 & 37.5 \\
\hline Long walking trips & 533 & 59.7 & 1202 & 66.5 & 706 & 54.5 & 3066 & 62.5 \\
\hline Walking trips & 892 & 100 & 1805 & 100 & 1295 & 100 & 4901 & 100 \\
\hline
\end{tabular}


Table 5 Walking trip origins models across various trip purposes

\begin{tabular}{|c|c|c|c|}
\hline All trips & Long trips & Short trips & All trips \\
\hline \multicolumn{4}{|l|}{ Work trips } \\
\hline $0.12^{* * *}$ & - & $0.023^{* * *}$ & Constant \\
\hline $0.00029^{* *}$ & - & $0.00042^{* * *}$ & Population density \\
\hline $0.00066^{* * *}$ & - & - & Link connectivity \\
\hline 0.066 & - & 0.123 & $\mathrm{R}^{2}$ \\
\hline 0.049 & - & 0.115 & $\operatorname{Adj}-R^{2}$ \\
\hline \multicolumn{4}{|c|}{ Educational trips } \\
\hline $0.259^{* *}$ & $0.28^{* * *}$ & $0.196^{* *}$ & Constant \\
\hline $0.001^{* *}$ & - & $0.00048^{* *}$ & Population Density \\
\hline- & $-0.126^{* *}$ & - & Car ownership \\
\hline $0.042^{* *}$ & $0.019^{*}$ & - & Link connectivity \\
\hline- & - & $-0.0022^{*}$ & Average link length \\
\hline 0.173 & 0.083 & 0.111 & $\mathrm{R}^{2}$ \\
\hline 0.158 & 0.066 & 0.094 & $\operatorname{Adj}-R^{2}$ \\
\hline \multicolumn{4}{|c|}{ Shopping trips } \\
\hline $0.215^{* * *}$ & $0.222^{* * *}$ & $0.102^{* * *}$ & Constant \\
\hline $0.001^{* * *}$ & - & $0.0009^{* * *}$ & Population density \\
\hline- & $-0.121^{* *}$ & - & Car ownership \\
\hline $0.129^{* *}$ & - & - & Job-pop balance \\
\hline $0.66^{* * *}$ & $0.19^{*}$ & $0.068^{* * *}$ & Link connectivity \\
\hline 0.396 & 0.076 & 0.288 & $\mathrm{R}^{2}$ \\
\hline 0.38 & 0.059 & 0.274 & $\operatorname{Adj}-R^{2}$ \\
\hline \multicolumn{4}{|c|}{ Return-to-home trips } \\
\hline $0.101^{* * *}$ & $0.092^{* * *}$ & $-0.017^{* * *}$ & Constant \\
\hline $0.0003^{*}$ & - & $0.001^{* * *}$ & Population density \\
\hline $0.362^{* * *}$ & $0.182^{* * *}$ & $0.151^{* * *}$ & Job-pop balance \\
\hline 0.479 & 0.117 & 0.29 & $\mathrm{R}^{2}$ \\
\hline 0.47 & 0.109 & 0.277 & $\operatorname{Adj}-R^{2}$ \\
\hline
\end{tabular}

$* * *{ }^{* *}$ and ${ }^{*}$ means $99 \%, 95 \%$ and $90 \%$ level of significance, respectively

\section{Results}

\subsection{Walking trip origins modeling}

In this section, walking trip origins models are represented (see Table 5).

According to the results (reported in Table 5), population density in short walking trips origins across all trip purposes was significant. Moreover, average link length in short educational walking trips origins ( $p$-value $=0.053)$, link connectivity in short shopping walking trips $(p$-value $=0.001)$ and job-population balance in short return-to-home trips origins ( $p$-value $=0.001$ ) were found significant. In long walking trips origins, car ownership and link connectivity in educational $(p$-value $=0.023)$ and shopping $(p$-value $=0.036)$
Table 6 Walking trip destinations models across various trip purposes

\begin{tabular}{|c|c|c|c|}
\hline All trips & Long trips & Short trips & All trips \\
\hline \multicolumn{4}{|l|}{ Work trips } \\
\hline \multirow[t]{2}{*}{$0.054^{* *}$} & $0.041^{*}$ & $0.160^{* * *}$ & Constant \\
\hline & - & $0.0004^{* * *}$ & Population density \\
\hline $0.218^{* * *}$ & $0.099^{* * *}$ & $0.086^{* *}$ & Job-pop balance \\
\hline 0.234 & 0.063 & 0.175 & $\mathrm{R}^{2}$ \\
\hline 0.227 & 0.054 & 0.16 & $\operatorname{Adj}-R^{2}$ \\
\hline \multicolumn{4}{|c|}{ Educational trips } \\
\hline \multirow[t]{2}{*}{$0.232^{* * *}$} & $0.088^{* *}$ & $0.006^{* * *}$ & Constant \\
\hline & - & $0.001^{* * *}$ & Population density \\
\hline $0.387^{* * *}$ & $0.262^{* * *}$ & $0.123^{* *}$ & Job-pop balance \\
\hline$-0.001^{*}$ & - & - & Average link length \\
\hline 0.234 & 0.118 & 0.112 & $\mathrm{R}^{2}$ \\
\hline 0.227 & 0.11 & 0.096 & Adj- $R^{2}$ \\
\hline \multicolumn{4}{|c|}{ Shopping trips } \\
\hline 0.232 & $0.165^{* *}$ & 0.045 & Constant \\
\hline $0.001 *$ & - & $0.002^{* * *}$ & Population density \\
\hline $0.548^{* * * *}$ & $0.244^{* *}$ & $0.209^{*}$ & Job-pop balance \\
\hline 0.338 & 0.048 & 0.164 & $\mathrm{R}^{2}$ \\
\hline 0.326 & 0.038 & 0.147 & Adj- $R^{2}$ \\
\hline \multicolumn{4}{|c|}{ Return-to-home trips } \\
\hline $0.113^{* * *}$ & $0.131^{* * *}$ & $0.113^{* * *}$ & Constant \\
\hline $0.001^{* * * *}$ & - & $0.001^{* * *}$ & population density \\
\hline- & $0.058^{*}$ & - & Job-pop balance \\
\hline$-0.001^{* *}$ & - & $-0.001^{* *}$ & Average link length \\
\hline 0.299 & 0.029 & 0.299 & $\mathrm{R}^{2}$ \\
\hline 0.286 & 0.02 & 0.286 & Adj- $R^{2}$ \\
\hline
\end{tabular}

$* * *,{ }^{* *}$ and $*$ means $99 \%, 95 \%$ and $90 \%$ level of significance, respectively

trips were significant. Moreover, job-population balance contributed to a significant increase in walking in returnto-home long walking trips origins ( $p$-value $=0.001$ ). None of the demographics and built environmental factors were not significant in long work walking trips. The goodness of fits in short and long walking trips' origins varied from 0.066 to 0.277 .

\subsection{Walking trip destinations models}

In this section, walking trip destination models are represented (See Table 6).

According to the results (reported in Table 6), population density in short walking trips destinations across all trip purposes and job-population balance in short work $(p$-value $=0.017)$, educational $(p$-value $=0.032)$ and shopping ( $p$-value $=0.067$ ) walking trips were found significant. Moreover, a shorter average link length was associated with a higher percentage of walking trips in 
short return-to-home trips ( $p$-value $=0.041$ ). A higher job-population balance in long walking trips was significantly increased percentage of walking trips across all trip purposes. The goodness of fits in short and long walking trips destination varied from 0.020 to 0.286 .

\section{Discussion}

\subsection{Walking trip origins modeling}

According to Table 5, in long educational and shopping trips (their origin zone is usually located at their residential zone), car ownership was significant, implying that individuals prefer to use their cars on longer trips. This would be more influential in shopping trips since the long trip length and additional baggage would put strain on a walker.

Connectivity measures in short and long educational and shopping trips were found significant. Link connectivity and the average length of links were influential in four models of short/long educational/shopping trips. Link connectivity ensures a denser network of minor roads. Its significance in educational trips may be due to lower car speeds in minor links, which provides safety for children on educational trips. Previous studies also verified the importance of safety in educational walking trips [47-50]. The negative sign in the average length of links means shorter average lengths in a TAZ resulted in a higher share of walking in that TAZ. It would be due to the lower speed of cars in these links since drivers do not have enough time to increase their speeds between two intersections. As is mentioned, the road network in Rasht is rudimentary because there are not separate streets and sidewalks.

As illustrated by the models, BE criteria resulted in higher goodness of fit in walking trip origins in shopping (Adj R-squared $=0.274$ ) and return-to-home (Adj $R$-squared $=0.277$ ) short trips compared to the long shopping (Adj R-squared $=0.059$ ) and return-to-home (Adj $R$-squared $=0.109$ ). The reason could be individuals have more free time on these trips versus work and educational trips, which shorter distances motivate individuals to walk.

\subsection{Walking trip destinations models}

Job-population balance, as a proxy of diversity, shows whether there is an equilibrium between job opportunities and residents in a TAZ. The positive sign of the index in the models means this balance positively impacts the increasing share of walking in a zone. Job-population balance was found influential in work, educational and shopping trips, in which the destination zone of trips is on the other side of individuals residing zone. This outcome suggests job-population balance is a proxy of the destination zone be interesting enough to encourage people to walk.

Overall, decomposing trips to short and long trips does not ensure a higher prediction power of trips comparing all trips. In three out of four production walking trip models and three out of four destination walking trip models, general models have higher goodness of fit.

\subsection{Discussion inferences}

The outcome shows that population density was significant in all eight origins and destinations models of short walking trips, while it was not in any long walking trip models. This finding highlights the importance of population density in short walking trips.

Job-population balance was significant for both short and long walking trips' destination in seven out of eight models. This finding highlights the importance of jobpopulation balance as an index of diversity criteria. In this study, in contrast with the previous studies $[8,10,11]$, diversity criterion (i.e., job-population balance) was more significant in the TAZs, which is not the individuals' residing area.

Generally, shopping and return-to-home short walking trips resulted in higher goodness of fit than work and educational short walking trips. While short shopping walking trips' goodness of fit were 0.274 and 0.147 and return-tohome walking trips' goodness of fit were 0.277 and 0.286 in origin and destination, the same measurements for work trips were 0.115 and 0.160 and for educational trips were 0.094 and 0.096 . The reason could be individuals' free time in shopping and return-to-home trips. Work and educational trips may limit individuals to a specific place for a fixed time. However, the models could not find any specific relationship in the goodness of fit in long walking trips. It worth noting that due to the abundant of factors involved and individuals' preferences, the goodness of fit in similar studies is usually not that high $[9,12,14,36,51]$.

\section{Conclusion}

In this study, 24 models have been developed to identify influencing factors on walking. In this regard, based on the diagram of the cumulative trips and lengths of trips, $600 \mathrm{~m}$ is used as a proxy between short and long walking trips.

The results found the impact of population density mostly on short walking trips, design (connectivity) factors on the share of walking in origin TAZs and job-population index, as a diversity index, on the share of walking in destination TAZs. The results show the goodness of fit is higher in short trips than long ones. It seems that 
shorter distances are more compatible with walking. In other words, as the distance increases, the impact of $\mathrm{BE}$ decreases.

This paper's results could provide more in-depth knowledge of different aspects of walking and move toward promoting sustainable transportation. Moreover, this paper could have implications for transportation, built environments, land-use, and even public health professionals and planners trying to effectively increase the overall use of walking, enhancing citizens' health indicators and individuals' quality of life.

Some limitations are important to point out. First, the exact length of trips is not reported in the database, and to evaluate the trip length, the distance between centroids of trip origin and destination have been used. In a macroscale analysis, $600 \mathrm{~m}$ is considered a threshold between short and long walking trips, based on the considerable difference in the cumulative diagram slope. However, this value may be affected by the scale of the study zones. Second, the major way of commuting is reported by individuals, not the details of their trip chain in a day.

Furthermore, there is information about individuals' origin and destination zone, not the exact route of their trip. If the exact route was given, all the zones involved could be considered in the analysis. Although wide ranges of indices are calculated, some others could help reach more profound results, such as density of bus stops, pedestrian catchment area, block density, and pedestrian route directness. Besides, various path attributes, such as slope, adjacent traffic volumes and presence (and width) of sidewalks, were not available in this study but could help reflect some key factors influencing walking for various trip purposes.

Acknowledgement The author thanks Lauren Cline for her useful review and discussion.

\section{Compliance with ethical standards}

Conflict of interest The author declares that he has no Conflict interests.

Open Access This article is licensed under a Creative Commons Attribution 4.0 International License, which permits use, sharing, adaptation, distribution and reproduction in any medium or format, as long as you give appropriate credit to the original author(s) and the source, provide a link to the Creative Commons licence, and indicate if changes were made. The images or other third party material in this article are included in the article's Creative Commons licence, unless indicated otherwise in a credit line to the material. If material is not included in the article's Creative Commons licence and your intended use is not permitted by statutory regulation or exceeds the permitted use, you will need to obtain permission directly from the copyright holder. To view a copy of this licence, visit http://creativecommons .org/licenses/by/4.0\%.

\section{References}

1. Ewing R, Cervero R (2010) Travel and the built environment: a meta-analysis. J Am Plan Assoc 76(3):265-294

2. Sharifi MS et al (2020) Exploring heterogeneous pedestrian stream characteristics at walking facilities with different angle intersections. Phys A 540:123112

3. Talen E, Koschinsky J (2013) The walkable neighborhood: A literature review. Int J Sustain Land Use Urb Plan 1(1):19

4. Park K et al (2020) Guidelines for a polycentric region to reduce vehicle use and increase walking and transit use. J Am Plan Assoc 86(2):236-249

5. Cervero R, Kockelman K (1997) Travel demand and the 3Ds: Density, diversity, and design. Transp Res Part D Transp Environ 2(3):199-219

6. Habibian $M$, Hosseinzadeh A (2018) Walkability index across trip purposes. Sustain Cities Soc 42:216-225

7. Hosseinzadeh A, Baghbani A (2020) Walking trip generation and built environment: a comparative study on trip purposes. Int J Traffic Transp Eng 10(3):1

8. Berrigan D, Pickle LW, Dill J (2010) Associations between street connectivity and active transportation. Int J Health Geogr $9(1): 20$

9. Dill J (2004) Measuring network connectivity for bicycling and walking. In: 83rd Annual meeting of the Transportation Research Board, Washington, DC

10. Gori S, Nigro M, Petrelli M (2014) Walkability indicators for pedestrian-friendly design. Transp Res Rec 2464(1):38-45

11. Frank LD et al (2005) Linking objectively measured physical activity with objectively measured urban form: findings from SMARTRAQ. Am J Prev Med 28(2):117-125

12. Schlossberg M, Brown N (2004) Comparing transit-oriented development sites by walkability indicators. Transp Res Rec 1887(1):34-42

13. Hooper P et al (2015) The building blocks of a 'Liveable Neighbourhood': identifying the key performance indicators for walking of an operational planning policy in Perth. West Australia Health Place 36:173-183

14. Frank LD et al (2010) The development of a walkability index: application to the neighborhood quality of life study. Br J Sports Med 44(13):924-933

15. Hosseinzadeh A (2019) Built environment and walking: short vs. long walking trips. arXiv preprint. arXiv:2001.00640

16. Hosseinzadeh et al (2021) Spatial analysis of shared e-scooter trips. J Transp Geogr (in press)

17. Hosseinzadeh, A., et al., E-scooters and Sustainability: Investigating the Relationship between the Density of E-Scooter Trips and Characteristics of Sustainable Urban Development. Sustainable Cities and Society, 2020: p. 102624.

18. Hatamzadeh Y, Habibian M, Khodaii A (2017) Walking behavior across genders in school trips, a case study of Rasht. Iran J Transp Health 5:42-54

19. Maghelal PK, Capp CJ (2011) Walkability: a review of existing pedestrian indices. J Urb Reg Inf Syst Assoc 23(2):1

20. Bentley $R$ et al (2018) A longitudinal study examining changes in street connectivity, land use, and density of dwellings and walking for transport in Brisbane, Australia. Environ Health Perspect 126(5):057003

21. Adams MA et al (2009) Validation of the Neighborhood Environment Walkability Scale (NEWS) items using geographic information systems. J Phys Activ Health 6(s1):S113-S123

22. Christian HE et al (2011) How important is the land use mix measure in understanding walking behaviour? Results from the RESIDE study. Int J Behav Nutr Phys Activ 8(1):55 
23. Sugiyama T et al (2019) Land use proportion and walking: application of isometric substitution analysis. Health place 57:352-357

24. Ewing R et al (2015) Varying influences of the built environment on household travel in 15 diverse regions of the United States. Urb Stud 52(13):2330-2348

25. Cervero R, Duncan M (2006) 'Which reduces vehicle travel more: jobs-housing balance or retail-housing mixing? J Am Plan Assoc 72(4):475-490

26. Hatamzadeh Y, Hosseinzadeh A (2020) Toward a deeper understanding of elderly walking for transport: an analysis across genders in a case study of Iran. J Transp Health 19:100949

27. Dobesova Z, Krivka T (2012) Walkability index in the urban planning: a case study in Olomouc city. Adv Spat Plan, p 179-197

28. JafariKang $M$, Khodadadifard $M$, Afandizadeh S (2017) Providing a decision-making method for evaluation of exclusive BRT lanes implementation using benefit-cost analysis-case study: Tehran BRT line 4. J Civil Eng Mater Appl 1(1):8-15

29. Kang MJ, Ataeian S, Amiripour SM (2020) A procedure for public transit OD matrix generation using smart card transaction data. Public Transport, p 1-20

30. Ferrer S, Ruiz T, Mars L (2015) A qualitative study on the role of the built environment for short walking trips. Transp Res Part F Traffic Psychol Behav 33:141-160

31. Mackett RL (2003) Why do people use their cars for short trips? Transportation 30(3):329-349

32. lacono M, Krizek K, El-Geneidy AM (2008) Access to destinations: How close is close enough? Estimating accurate distance decay functions for multiple modes and different purposes.

33. Neilson GK, Fowler WK (1972) Relation between transit ridership and walking distances in a low-density Florida retirement area. Highw Res Record, 403

34. Daniels R, Mulley C (2013) Explaining walking distance to public transport: the dominance of public transport supply. JTrans Land Use 6(2):5-20

35. Yang Y, Diez-Roux AV (2012) Walking distance by trip purpose and population subgroups. Am J Prev Med 43(1):11-19

36. Frank LD, Pivo G (1994) Impacts of mixed use and density on utilization of three modes of travel: single-occupant vehicle, transit, and walking. Transp Res Rec 1466:44-52

37. Gehrke SR, Clifton KJ (2017) A pathway linking smart growth neighborhoods to home-based pedestrian travel. Travel Behav Soc 7:52-62
38. Handy SL (1978) Regional versus local accessibility: neo-traditional development and its implications for non-work travel. Built Environ 1992:253-267

39. Perchoux $C$ et al (2019) Walking, trip purpose, and exposure to multiple environments: a case study of older adults in Luxembourg. J Transp Health 13:170-184

40. Andishkar consulting engineers (2011) Rasht comprehensive transportation planning study. Municipality of Rasht, Rasht

41. Azimi N (2005) Restructuring urban morphology: a case study of Rasht, Iran

42. Bahrainy $H$ (1998) Urban planning and design in a seismicprone region (the case of Rasht in Northern Iran). J Urb Plan Dev 124(4):148-181

43. Sohn K, Shim H (2010) Factors generating boardings at metro stations in the Seoul metropolitan area. Cities 27(5):358-368

44. Sung H, Oh J-T (2011) Transit-oriented development in a highdensity city: identifying its association with transit ridership in Seoul. Korea Cities 28(1):70-82

45. Agrawal AW, Schimek P (2007) Extent and correlates of walking in the USA. Transp Res Part D Transp Environ 12(8):548-563

46. Karimpour A, Ariannezhad A, Wu Y-J (2019) Hybrid data-driven approach for truck travel time imputation. IET Intell Transp Syst 13(10):1518-1524

47. Buliung RN et al (2017) Children's independent mobility in the City of Toronto Canada. Travel Behav Soc 9:58-69

48. Rothman $L$ et al (2017) The school environment and student car drop-off at elementary schools. Travel Behav Soc 9:50-57

49. Bakhshi AK, Ahmed MM (2021) Practical advantage of crossed random intercepts under Bayesian hierarchical modeling to tackle unobserved heterogeneity in clustering critical versus non-critical crashes. Accid Anal Prev 149:105855

50. Hosseinzadeh A, Kluger R (2021) Do EMS times associate with injury severity? Accid Anal Prev (in press)

51. Habibian M, Avaz Z, Hosseinzadeh A (2015) Sociological study of influence of citizen's traffic ethics on driving violations: case study of Tehran, Iran. In: 94th annual meeting of the Transportation Research Board (No. 15-6029)

Publisher's Note Springer Nature remains neutral with regard to jurisdictional claims in published maps and institutional affiliations. 